\title{
The Association between Influenza Vaccination and the Risk of SARS-CoV-2 Infection, Severe Illness, and Death: A Systematic Review of the Literature
}

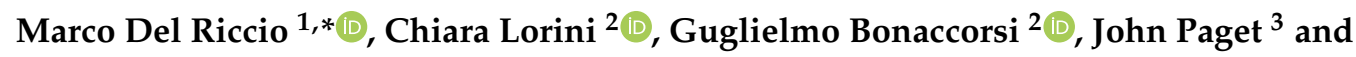 \\ Saverio Caini ${ }^{4}[\mathbb{D}$ \\ 1 Postgraduate Medical School in Public Health, University of Florence, 50134 Florence, Italy \\ 2 Department of Health Sciences, University of Florence, 50134 Florence, Italy; chiara.lorini@unifi.it (C.L.); \\ guglielmo.bonaccorsi@unifi.it (G.B.) \\ 3 Netherlands Institute for Health Services Research (Nivel), 3513 Utrecht, The Netherlands; J.Paget@nivel.nl \\ 4 Molecular and Lifestyle Epidemiology Branch, Institute for Cancer Research, Prevention and Clinical \\ Network (ISPRO), 50139 Florence, Italy; s.caini@ispro.toscana.it \\ * Correspondence: marco.delriccio@unifi.it
}

Received: 28 September 2020; Accepted: 23 October 2020; Published: 27 October 2020

\begin{abstract}
We reviewed the association between seasonal influenza vaccination and the risk of SARS-CoV-2 infection or complicated illness or poor outcome (e.g., severe disease, need for hospitalization or ventilatory support, or death) among COVID-19 patients. None of the studies that were reviewed $(n=12)$ found a significant increase in the risk of infection or in the illness severity or lethality, and some reported significantly inverse associations. Our findings support measures aimed at raising influenza vaccination coverage in the coming months.
\end{abstract}

Keywords: SARS-CoV-2; influenza vaccine; systematic review; infection; severity; risk

\section{Introduction}

There has been an important debate recently in the scientific community and the media about the relationship between influenza vaccination and COVID-19. Influenza and COVID-19 are respiratory viral illnesses that may be clinically indistinguishable and tend to be life-threatening in largely overlapping population subgroups (e.g., the elderly and people suffering from chronic health conditions). Moreover, because they are respiratory virus illnesses, their peak of activity may occur in the same period of the year (i.e., winter months in temperate countries). Based on the above considerations, most health professionals have advocated in favor of strengthening influenza vaccination programs, arguing that rising vaccine coverage could help improve COVID-19 patient management by allowing easier differential diagnosis and reducing the overload of healthcare systems, particularly intensive care units (ICUs) [1].

Public health decisions should be based as much as possible on the best available evidence regarding any benefits and drawbacks that the proposed intervention may be expected to entail, and because the influenza season is rapidly approaching in the Northern Hemisphere, a literature review on this topic is urgently needed. Here, we conducted a systematic review of the articles that examined whether influenza vaccination affects the risk of being infected with the SARS-CoV-2 virus, and the risk of complicated illness or poor outcome (e.g., severe disease, need for hospitalization or ventilatory support, or death) among COVID-19 patients. 


\section{Materials and Methods}

The literature search was performed on 31 August 2020 by interrogating the MEDLINE, Embase and medRxiv databases for both peer-reviewed and non-peer-reviewed articles in any language (as long as an English abstract was available), using the following string: "SARS-CoV-2 OR COVID" AND "influenza OR flu" AND "vaccine*". All identified articles were first independently screened by two researchers (MDR and SC) based on their title, and any considered potentially eligible for inclusion by either researcher was then obtained and read in full text. Any disagreement on the eligibility of a given article was resolved by consensus.

The literature search was then extended to the reference lists of all of the articles that were obtained in full copy (regardless of their final inclusion in the review). To be eligible for inclusion, an article had to be an original report based on individual-level data; studies relying on aggregated data (e.g., ecological studies reporting correlations $[2,3]$ ) were not retained because of their higher risk of bias. Letters and commentaries with no original data were also discarded.

Information and data related to the study design, size, and outcome, the participants' mean/median age, the laboratory method used (if applicable), and the main results of the study were retrieved. Risk ratios (RRs), odds ratios (ORs), or hazard ratios (HRs) were reported whenever available, in addition to the information about any statistical adjustments that were made. The study quality was assessed using the Newcastle-Ottawa Scale (NOS), according to which the risk of bias in a given study is classified as low (overall score 7 to 9), moderate/high (4 to 6), or very high (0 to 3) [4].

\section{Results}

The literature search identified 1619 non-duplicate entries, of which 1461 were excluded based on their title. The remaining 158 articles were read in full copy, and an additional article was identified in their reference lists. Finally, twelve independent articles met all inclusion criteria and were retained (Figure 1).

Overall, the studies had good methodological quality, with the risk of bias judged to be low (overall score 7-9) in eight of twelve studies (Supplementary Materials File S1). The lack of statistical adjustments and the reliance on self-reported assessment of exposure (i.e., vaccination status) were the main issues for the four studies considered at moderate/high risk of bias.

Seven articles [7-13] focused on the association between influenza vaccination and the risk of SARS-CoV-2 infection (Table 1): these encompassed a total of 242,323 subjects, of which $56.6 \%$ were contributed by Pawlowski et al. [12] and 32.6\% by Vila-Córcoles et al. [13]. Most studies were based on subjects from the general population, with the exception of the two smallest studies, which included 203 firefighters and paramedics from the USA [8], and 640 liver transplant patients from Italy [9]. The studies also differed in that they were based on a varying proportion of symptomatic and asymptomatic individuals. The laboratory diagnostic method varied across studies, with (qRT-) PCR being used in three of them. No statistical adjustment was made in four studies: Aziz et al. [7] and Donato et al. [9] found no significant association, whereas COVID-19 cases were significantly less likely to be vaccinated than test-negative subjects in the studies by Jehi et al. [10] (which separately reported on two independent cohorts) and Caban-Martinez et al. [8]. Three studies reported measures of association adjusted by age, gender, comorbidities, and other potential confounders, all of which found that influenza vaccinees were significantly less likely to become infected with the SARS-CoV-2 virus than non-vaccinees. Noale et al. [11] found a reduced risk among subjects aged less than 65 years (odds ratio (OR) 0.85, 95\% confidence interval (CI) 0.74-0.98, $p=0.024$; the OR among those aged $\geq 65$ years was of similar magnitude, 0.87 , but not statistically significant, $p=0.483$ ). On the contrary, the association was stronger in the $\geq 65$ years subgroup (relative risk $0.74,95 \% \mathrm{CI} 0.61-0.89, p<0.01$ ) in the study by Pawlowski et al. [12], and also achieved statistical significance $(p<0.03)$ in the whole population. Finally, a statistically significant inverse association (hazard ratio $0.63,95 \%$ CI $0.43-0.92$, $p=0.015)$ emerged among adults aged $\geq 50$ years enrolled in the study by Vila-Córcoles et al. [13]. 
Table 1. Main features and results of studies on the association between influenza vaccination and the risk of infection with SARS-CoV-2.

\begin{tabular}{|c|c|c|c|c|c|}
\hline Author & Study Sample & Age (Years) & Laboratory Method & Main Result & Adjustment \\
\hline Aziz et al. [7] & $\begin{array}{l}\text { Subjects participating in a } \\
\text { community-based cohort } \\
\text { study in Bonn, Germany } \\
\quad(n=4755)\end{array}$ & $\geq 30($ mean 55.2, SD 13.6) & ELISA and PRNT & $\begin{array}{l}\text { No statistically significant } \\
\text { association (no details available) }\end{array}$ & None \\
\hline Caban-Martinez et al. [8] & $\begin{array}{l}\text { Frontline firefighters and } \\
\text { paramedics of a fire } \\
\text { department in Florida, } \\
\text { USA }(n=203) \text { (a) }\end{array}$ & $\geq 21$ & $\begin{array}{l}\text { Point-of-care IgM-IgG } \\
\text { LFIA }\end{array}$ & $\begin{array}{l}\text { COVID-19 cases were significantly } \\
\text { less likely to be vaccinated than } \\
\text { controls }(p=0.027)\end{array}$ & None \\
\hline Donato et al. [9] & $\begin{array}{l}\text { Liver transplant patients } \\
\text { in Italy }(n=640)\end{array}$ & $\geq 20$ (median 63) & Not specified & $\begin{array}{l}\text { No statistically significant } \\
\text { association }(p=0.238)\end{array}$ & None \\
\hline \multirow{2}{*}{ Jehi et al. [10] } & $\begin{array}{l}\text { Subjects tested in several } \\
\text { clinics in Ohio, USA } \\
(n=11,672)(b)\end{array}$ & $\begin{array}{c}\text { Any age } \\
\text { COVID-19 negative: median 46.9, } \\
\text { IQR 31.6-62.9 } \\
\text { COVID-19 positive: median 54.2, } \\
\text { IQR 38.8-65.9 }\end{array}$ & \multirow{2}{*}{ RT-PCR } & $\begin{array}{l}\text { COVID-19 cases were significantly } \\
\text { less likely to be vaccinated than } \\
\text { controls }(p<0.001)\end{array}$ & \multirow{2}{*}{ None } \\
\hline & $\begin{array}{l}\text { Subjects tested in several } \\
\text { clinics in Florida, USA } \\
\qquad(n=2295)(\mathrm{b})\end{array}$ & $\begin{array}{c}\text { Any age } \\
\text { COVID-19 negative: median 56.0, } \\
\text { IQR 41.9-67.5 } \\
\text { COVID-19 positive: median 52.6, } \\
\text { IQR 36.7-63.1 }\end{array}$ & & $\begin{array}{l}\text { COVID-19 cases were significantly } \\
\text { less likely to be vaccinated than } \\
\text { controls }(p=0.011)\end{array}$ & \\
\hline Noale et al. [11] & $\begin{array}{c}\text { Subjects years } \\
\text { participating in a } \\
\text { web-based survey in Italy } \\
(n=6650) \text { (c) }\end{array}$ & $\geq 18($ mean 48.0, SD 17.7$)$ & Not specified & $\begin{array}{c}\text { Vaccinated subjects }<65 \text { years old } \\
\text { were significantly less likely to be } \\
\text { infected (OR } 0.85,95 \% \text { CI } 0.74-0.98 \\
p=0.024 \text { ). No statistically } \\
\text { significant association among } \\
\text { subjects } \geq 65 \text { years (OR } 0.87,95 \% \\
\text { CI } 0.59-1.28, p=0.483 \text { ) }\end{array}$ & $\begin{array}{l}\text { Age, gender, education, } \\
\text { comorbidities, other }\end{array}$ \\
\hline Pawlowski et al. [12] & $\begin{array}{l}\text { Subjects who received } \\
\text { SARS-CoV-2 testing at } \\
\text { Mayo Clinic, USA } \\
(n=137,037)\end{array}$ & Any age & PCR & $\begin{array}{c}\text { Subjects vaccinated in the past year } \\
\text { were significantly less likely to be } \\
\text { infected (RR } 0.85,95 \% \text { CI } 0.75-0.96 \\
p=0.03 \text { ). The association was } \\
\text { stronger in the } \geq 65 \text { years subgroup } \\
\text { (RR } 0.74,95 \% \text { CI } 0.61-0.89 \\
p<0.01 \text { ). }\end{array}$ & $\begin{array}{l}\text { Propensity score matching } \\
\text { (d) and multiple } \\
\text { comparison }\end{array}$ \\
\hline
\end{tabular}


Table 1. Cont

\begin{tabular}{|c|c|c|c|c|c|}
\hline Author & Study Sample & Age (Years) & Laboratory Method & Main Result & Adjustment \\
\hline Vila-Córcoles et al. [13] & $\begin{array}{l}\text { All subjects tested at } \\
\text { primary healthcare center } \\
\text { in Tarragona area, Spain } \\
(n=79,071)\end{array}$ & $\geq 50$ & RT-PCR & $\begin{array}{c}\text { Vaccinated subjects were } \\
\text { significantly less likely to be } \\
\text { infected (HR } 0.63,95 \% \text { CI } 0.43-0.92, \\
p=0.015)\end{array}$ & $\begin{array}{l}\text { Age, gender, vaccination } \\
\text { history, comorbidities }\end{array}$ \\
\hline \multicolumn{6}{|c|}{$\begin{array}{l}\text { (a) } 185 \text { patients had information on influenza vaccination available and were included in the analyses reported here. (b) Criteria for testing were: any of recent travel history to high-risk } \\
\text { area, symptoms of respiratory illness (cough, fever, flu-like symptoms), physician discretion, or known contact with a COVID-19 case, during } 12-17 \text { March } 2020 \text {; any of age }>60 \text { years or } \\
\text { <26 months, comorbidities, immune therapy, known contact with a COVID-19 case from March } 18 \text { afterwards. (c) A total of } 198,828 \text { subjects participated (on a voluntary basis) in the } \\
\text { web-based survey, of which } 6650 \text { reported SARS-CoV-2 nasopharyngeal swab testing and were included in the analyses. (d) Covariates considered in the propensity score matching: } \\
\text { demographics (age, gender, race, ethnicity), county-level COVID-19 incidence and test-positive rate, comorbidities, pregnancy, and number of other vaccines. ELISA: enzyme-linked } \\
\text { immunosorbent assay. LFIA: lateral flow immunoassay. PRNT: plaque reduction neutralization test. RT-PCR: reverse transcriptase-polymerase chain reaction. HR: hazard ratio. OR: odds } \\
\text { ratio. RR: relative risk. CI: confidence interval. SD: standard deviation. IQR: inter-quartile range. }\end{array}$} \\
\hline
\end{tabular}




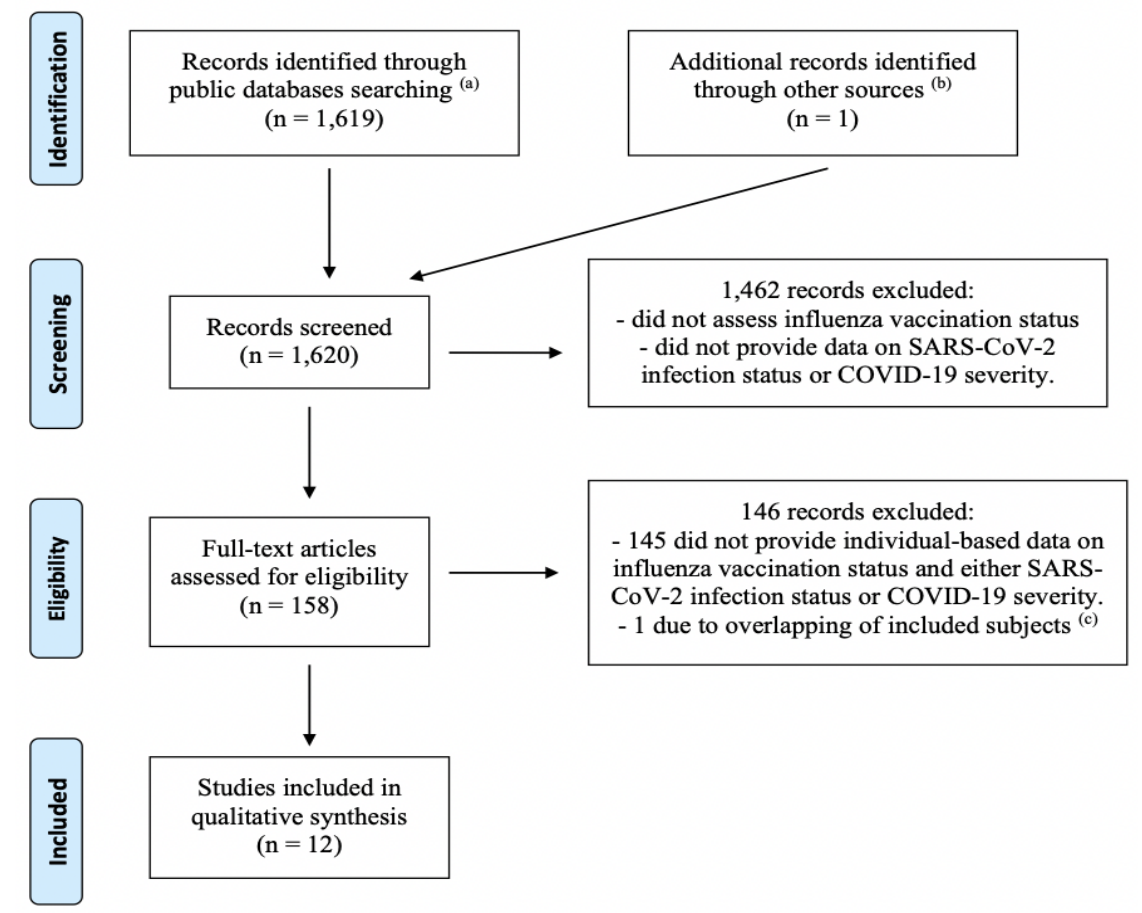

Figure 1. Flow-chart of the literature review (up to 31 August 2020) of studies investigating the association between influenza vaccination status and either the risk of being infected with the SARS-CoV-2 virus, or the risk of severe illness or death among COVID-19 patients. (a) MEDLINE, Embase, MedRxiv. (b) Reference list of records found through public databases. (c) The study by Santos et al. [5] was excluded due to probable overlap of the study population with the article by Fink et al. [6]. Both studies were based on data from hospitalizations for COVID-19 patients in Brazil registered in a national surveillance system. The study by Santos et al. was less recent and based on a smaller population, and examined fewer outcomes, compared to Fink et al., and, unlike the latter, performed no statistical adjustments.

Five articles [6,14-17] reported on the association between influenza vaccination and the risk of severe illness and/or death among COVID-19 patients (Table 2). The total number of patients was 111,820 , of which the majority $(82.9 \%)$ were contributed by Fink et al. [6]. The latter was the only study encompassing a minority $(16 \%)$ of non-laboratory-confirmed patients. Jehi et al. [14] and Murillo-Zamora et al. [15] found that the likelihood of being vaccinated against influenza was significantly $(p<0.001)$ or, respectively, nearly significantly $(p=0.073)$ lower among patients who required to be hospitalized compared to those who did not. Likewise, Fink et al. [6] reported a significantly lower odds of requiring intensive care or respiratory support among influenza vaccinees vs. non-vaccinees. The latter study also found that vaccinated COVID-19 patients were at significantly reduced risk of dying compared to non-vaccinated patients (OR 0.82, 95\% CI 0.75-0.89, $p<0.01$ ), but this finding was not confirmed in the studies by Ortiz-Prado et al. [16] and Poblador-Plou et al. [17]. 
Table 2. Main features and results of studies on the association between influenza vaccination and the risk of severe illness or death among COVID-19 patients.

\begin{tabular}{|c|c|c|c|c|c|}
\hline Author & Study Sample & Age (Years) & Outcome & Main Result & Adjustment \\
\hline \multirow{2}{*}{ Jehi et al. [14] } & $\begin{array}{l}\text { Laboratory-confirmed } \\
\text { COVID-19 patients in Ohio and } \\
\text { Florida, USA }(n=2852) \text { (a) }\end{array}$ & $\begin{array}{l}\text { Any age } \\
\text { Not hospitalized: median 50.8, } \\
\text { IQR 35.8-64.4 } \\
\text { Hospitalized: median 64.4, IQR } \\
\quad 54.8-76.6\end{array}$ & Severe illness & $\begin{array}{l}\text { Severe cases (requiring hospitalization) } \\
\text { were significantly less likely to be } \\
\text { vaccinated than non-severe cases } \\
\qquad(p<0.001) \text { (b) }\end{array}$ & None \\
\hline & $\begin{array}{l}\text { Laboratory-confirmed } \\
\text { COVID-19 patients in Ohio and } \\
\text { Florida, USA }(n=1684) \text { (a) }\end{array}$ & $\begin{array}{c}\text { Any age } \\
\text { Not hospitalized: median 45.6, } \\
\text { IQR 30.5-65.9 } \\
\text { Hospitalized: median 64.9, IQR } \\
\text { 52.5-76.8 }\end{array}$ & Severe illness & $\begin{array}{l}\text { Severe cases (requiring hospitalization) } \\
\text { were significantly less likely to be } \\
\text { vaccinated than non-severe cases } \\
\qquad(p<0.001)(b)\end{array}$ & None \\
\hline Murillo-Zamora et al. [15] & $\begin{array}{l}\text { Laboratory-confirmed } \\
\text { COVID-19 patients in Mexico } \\
\qquad(n=740)\end{array}$ & $\geq 15$ (mean 43.7, SD 14.9) & Severe illness & $\begin{array}{l}\text { Severe cases (dyspnoea requiring } \\
\text { hospitalization) were non-significantly } \\
\text { less likely to be vaccinated than } \\
\text { non-severe cases }(p=0.073)\end{array}$ & None \\
\hline \multirow[t]{2}{*}{ Fink et al. [6] } & \multirow{2}{*}{$\begin{array}{l}\text { All clinically confirmed } \\
\text { COVID-19 patients in Brazil } \\
(n=92,664, \text { of which } 84 \% \\
\text { laboratory-confirmed) (c) }\end{array}$} & \multirow[t]{2}{*}{ Any age (median 59) } & Severe illness & $\begin{array}{c}\text { Vaccinated patients were significantly } \\
\text { less likely to require intensive care (OR } \\
0.92,95 \% \mathrm{CI} 0.86-0.99, p<0.05) \text { or } \\
\text { respiratory support }(\mathrm{OR} 0.81,95 \% \mathrm{CI} \\
0.74-0.88, p<0.01)\end{array}$ & \multirow{2}{*}{$\begin{array}{l}\text { Age, SES, comorbidities, } \\
\text { other }\end{array}$} \\
\hline & & & Death & $\begin{array}{l}\text { Vaccinated patients were at } \\
\text { significantly reduced risk of death (OR } \\
0.82,95 \% \text { CI } 0.75-0.89, p<0.01 \text { ) (d) }\end{array}$ & \\
\hline Ortiz-Prado et al. [16] & $\begin{array}{l}\text { All laboratory-confirmed } \\
\text { COVID-19 patients in Ecuador } \\
(n=9468)\end{array}$ & $\begin{array}{c}\text { Any age } \\
\text { Men: median 42, IQR 32-56 } \\
\text { Women: median 39, IQR 30-54 }\end{array}$ & Death & $\begin{array}{c}\text { No statistically significant association } \\
\text { (OR among vaccinated patients: } 0.71 \text {, } \\
95 \% \text { CI } 0.23-2.17 \text { ) }\end{array}$ & $\begin{array}{l}\text { Age, gender, } \\
\text { comorbidities }\end{array}$ \\
\hline Poblador-Plou et al. [17] & $\begin{array}{c}\text { All laboratory-confirmed } \\
\text { COVID-19 patients in Aragon, } \\
\text { Spain, with follow-up } \geq 30 \text { days } \\
\qquad(n=4412)\end{array}$ & Any age (mean 67.7, SD 20.7) & Death & $\begin{array}{l}\text { No significant differences in the } \\
\text { proportion of vaccination between } \\
\text { deceased and alive patients after } \\
\text { adjusting by age ( } p=0.110 \text { among men, } \\
p=0.126 \text { among women })\end{array}$ & Age \\
\hline
\end{tabular}

(a) COVID-19 patients diagnosed from 8 March to 1 May were included in a "development" cohort (used to build a predictive model), and patients diagnosed afterwards (until 5 June) were included in a "validation" cohort (for model validation). Results were only provided separately for the two cohorts. (b) Influenza vaccination was included in the predictive model for the risk of hospitalization for COVID-19 patients. (c) The number of patients with available information on both vaccination status and the outcome of interest and that, therefore, were included in the analyses reported here were: 26,260 for the risk of requiring intensive care; 25,959 for the risk of requiring respiratory support; and 19,274 for the risk of death (d) Analysis restricted to laboratory-confirmed COVID-19 cases only. Results were confirmed also when including non-laboratory confirmed patients (OR $0.84,95 \%$ CI $0.77-0.91, p<0.01$ ).

OR: odds ratio. CI: confidence interval. SES: socio-economic status. SD: standard deviation. IQR: inter-quartile range. 


\section{Discussion}

Influenza epidemics recur each year and the persistence of SARS-CoV-2 circulation in the upcoming months may expose healthcare systems to a severe risk of resource scarcity. Influenza vaccination is the cornerstone of influenza prevention, thus attaining higher vaccine coverage has been widely acknowledged as a public health priority [18]. Concerns about a possible association between influenza vaccination and the risk of coronavirus infection were raised based on Wolff's paper, which examined endemic coronaviruses circulating in the USA in the 2017-2018 season, much earlier than the emergence of the SARS-CoV-2 virus [19]. After reviewing the existing literature on the topic, we can safely conclude that influenza vaccination is unlikely to be associated with an increase in SARS-CoV-2 risk of infection or with COVID-19 severity and the risk of associated death. In fact, most reviewed studies detected an inverse relationship, which was unexpected and even disconcerting given that influenza vaccines are not designed to protect from SARS-CoV-2.

The studies included in this review are heterogeneous in many aspects, including their design, sample size, and inclusion criteria. In terms of study populations, some studies included individuals of all ages, while others focused only on the adult population. Unfortunately, only a few studies focused specifically on high-risk groups. In fact, only Noale et al. [11] and Pawlowski et al. [12] reported results specific to participants of $\geq 65$ years, and no study reported on pediatric populations. In addition, the study by Donato et al. [9] was based on a population of transplanted patients, and caution is required in extrapolating its results to the general population. Moreover, the studies included in this review [7-13] used different testing criteria to assess the presence of SARS-CoV-2 infection, depending on the testing policy implemented in the area in which the study was conducted, and different diagnostic tests (of the seven studies specifically focusing on this aspect, three used molecular diagnosis with PCR $[10,12,13]$, two performed antibody-based tests $[7,8]$, and two did not specify the diagnostic tool that was used $[9,11])$. Furthermore, it must be acknowledged that all reviewed studies are retrospective and observational in nature, and thus likely to be subject to bias, and that not all studies reported measures of association adjusted by the relevant confounders. Finally, influenza vaccine effectiveness is difficult to estimate accurately and fluctuates across years, which may represent a further source of uncertainty in interpreting and comparing the results of the different studies [20]. Because of these several limitations, we recommend that further studies be conducted to confirm these preliminary findings and examine their validity in different population subgroups.

\section{Conclusions}

In conclusion, our review finds that, based on our knowledge (until the end of August 2020), public health measures aimed at raising influenza vaccine coverage should be encouraged. There is no evidence to suggest that this would have a negative impact on populations in terms of SARS-CoV-2 related infections, illness, or deaths.

Supplementary Materials: The following are available online at http://www.mdpi.com/1660-4601/17/21/7870/s1. File S1.

Author Contributions: Conceptualization, M.D.R., C.L., G.B., J.P. and S.C.; methodology, M.D.R., C.L., G.B., J.P. and S.C.; validation, M.D.R., C.L., G.B., J.P. and S.C.; formal analysis, M.D.R. and S.C.; investigation, M.D.R., J.P. and S.C.; resources, M.D.R., C.L., G.B., J.P. and S.C.; data curation, M.D.R., C.L., G.B., J.P. and S.C.; writing-original draft preparation, M.D.R. and S.C.; writing—review and editing, M.D.R., C.L., G.B., J.P. and S.C.; visualization, M.D.R., C.L., G.B., J.P. and S.C.; supervision, C.L., G.B., J.P. and S.C.; project administration, C.L., G.B., J.P. and S.C. All authors have read and agreed to the published version of the manuscript.

Funding: This research received no external funding.

Conflicts of Interest: The authors declare the following financial interests/personal relationships which may be considered as potential competing interests: [Marco Del Riccio, Chiara Lorini, Guglielmo Bonaccorsi, Saverio Caini declare no known competing financial interests or personal relationships that could have appeared to influence the work reported in this paper. John Paget declares that NIVEL has received unrestricted research grants from WHO, Sanofi Pasteur and the Foundation for Influenza Epidemiology]. 


\section{References}

1. Li, Q.; Tang, B.; Bragazzi, N.L.; Xiao, Y.; Wu, J. Modeling the impact of mass influenza vaccination and public health interventions on COVID-19 epidemics with limited detection capability. Math. Biosci. 2020, 325, 108378. [CrossRef] [PubMed]

2. Zanettini, C.; Omar, M.; Dinalankara, W.; Imada, E.L.; Colantuoni, E.; Parmigiani, G.; Marchionni, L. Influenza Vaccination and COVID19 Mortality in the USA. medRxiv 2020. Available online: https://www.medrxiv.org/ content/10.1101/2020.06.24.20129817v1 (accessed on 26 June 2020).

3. Marín-Hernández, D.; Schwartz, R.E.; Nixon, D.F. Epidemiological evidence for association between higher influenza vaccine uptake in the elderly and lower COVID-19 deaths in Italy. J. Med. Virol. 2020. [CrossRef] [PubMed]

4. Wells, G.; Shea, B.; O'Connel, D.; Peterson, J.; Welch, V.; Losos, M.; Tugwell, P. The Newcastle Ottawa Scale (NOS) for Assessing the Quality of Nonrandomized Studies in Meta-Analyses. 2013. Available online: http://www.ohri.ca/programs/clinical_epidemiology/oxford.asp (accessed on 19 October 2020).

5. Santos, M.; Lucena, E.E.S.; Lima, K.C.; Brito, A.A.C.; Bonfada, D. Survival and predictors of deaths of patients hospitalized due to COVID-19 from a retrospective and multicenter cohort study in Brazil. medRxiv 2020. Available online: https://www.medrxiv.org/content/10.1101/2020.06.07.20125047v1 (accessed on 9 June 2020).

6. Fink, G.; Orlova-Fink, N.; Schindler, T.; Grisi, S.; Ferrer, A.P.; Daubenberger, C.; Brentani, A. Inactivated trivalent influenza vaccine is associated with lower mortality among Covid-19 patients in Brazil. medRxiv 2020. Available online: https://www.medrxiv.org/content/10.1101/2020.06.29.20142505v1 (accessed on 1 July 2020).

7. Aziz, N.A.; Corman, V.M.; Echterhoff, A.K.C.; Richter, A.; Schmandke, A.; Schmidt, M.L.; Schmidt, T.H.; De Vries, F.M.; Drosten, C.; Breteler, M.M.B. Seroprevalence and correlates of SARS-CoV-2 neutralizing antibodies: Results from a population-based study in Bonn, Germany. medRxiv 2020. Available online: https://www.medrxiv.org/content/10.1101/2020.08.24.20181206v1 (accessed on 29 August 2020).

8. Caban-Martinez, A.J.; Schaefer-Solle, N.; Santiago, K.; Louzado-Feliciano, P.; Brotons, A.; Gonzalez, M.; Issenberg, S.B.; Kobetz, E. Epidemiology of SARS-CoV-2 antibodies among firefighters/paramedics of a US fire department: A cross-sectional study. Occup. Environ. Med. 2020. [CrossRef] [PubMed]

9. Donato, M.F.; Invernizzi, F.; Lampertico, P.; Rossi, G. Health Status of Patients Who Underwent Liver Transplantation During the Coronavirus Outbreak at a Large Center in Milan, Italy. Clin. Gastroenterol. Hepatol. 2020, 18, 2131-2133. [CrossRef] [PubMed]

10. Jehi, L.; Ji, X.; Milinovich, A.; Erzurum, S.; Rubin, B.P.; Gordon, S.; Young, J.B.; Kattan, M.W. Individualizing Risk Prediction for Positive Coronavirus Disease 2019 Testing: Results from 11,672 Patients. Chest 2020, 158, 1364-1375. [CrossRef] [PubMed]

11. Noale, M.; Trevisan, C.; Maggi, S.; Antonelli Incalzi, R.; Pedone, C.; Di Bari, M.; Adorni, F.; Jesuthasan, N.; Sojic, A.; Galli, M.; et al. The Association between Influenza and Pneumococcal Vaccinations and SARS-Cov-2 Infection: Data from the EPICOVID19 Web-Based Survey. Vaccines 2020, 8, 471. [CrossRef] [PubMed]

12. Pawlowski, C.; Puranik, A.; Bandi, H.; Venkatakrishnan, A.J.; Agarwal, V.; Kennedy, R.; O'Horo, J.C.; Gores, G.J.; Williams, A.W.; Halamka, J.; et al. Exploratory analysis of immunization records highlights decreased SARS-CoV-2 rates in individuals with recent non-COVID-19 vaccinations. medRxiv 2020. Available online: https://www.medrxiv.org/content/10.1101/2020.07.27.20161976v2 (accessed on 29 July 2020).

13. Vila-Córcoles, Á.; Ochoa-Gondar, O.; Torrente-Fraga, C.; Vila-Rovira, Á.; Satué-Gracia, E.; Hospital-Guardiola, I.; de Diego-Cabanes, C.; Gómez-Bertomeu, F.; Basora-Gallisà, J. Evaluación de la incidencia y perfil de riesgo de Covid-19 según comorbilidad previa en adultos $\geq 50$ años del área de Tarragona [Evaluation of incidence and risk profile for suffering Covid-19 infection by underlying conditions among middle-aged and older adults in Tarragona]. Rev. Esp. Salud Publica 2020, 94, e202006065. [PubMed]

14. Jehi, L.; Ji, X.; Milinovich, A.; Erzurum, S.; Merlino, A.; Gordon, S.; Young, J.B.; Kattan, M.W. Development and validation of a model for individualized prediction of hospitalization risk in 4536 patients with COVID-19. PLoS ONE 2020, 15, e0237419. [CrossRef] [PubMed]

15. Murillo-Zamora, E.; Trujillo, X.; Huerta, M.; Ríos-Silva, M.; Mendoza-Cano, O. Male gender and kidney illness associated with an increased risk of severe laboratory-confirmed coronavirus disease. BMC Infect. Dis. 2020, 20, 674. [CrossRef] [PubMed] 
16. Ortiz-Prado, E.; Simbana-Rivera, K.; Diaz, A.M.; Barreto, A.; Moyano, C.; Arcos, V.; Vasconez-Gonzalez, E.; Paz, C.; Simbana-Guaycha, F.; Molestina-Luzuriaga, M.; et al. Epidemiological, socio-demographic and clinical features of the early phase of the COVID-19 epidemic in Ecuador. medRxiv 2020. Available online: https://www.medrxiv.org/content/10.1101/2020.05.08.20095943v2 (accessed on 18 May 2020).

17. Poblador-Plou, B.; Carmona-Pírez, J.; Ioakeim-Skoufa, I.; Poncel-Falcó, A.; Bliek-Bueno, K.; Cano-Del Pozo, M.; Gimeno-Feliú, L.A.; González-Rubio, F.; Aza-Pascual-Salcedo, M.; Bandrés-Liso, A.C.; et al. Baseline Chronic Comorbidity and Mortality in Laboratory-Confirmed COVID-19 Cases: Results from the PRECOVID Study in Spain. Int. J. Environ. Res. Public Health 2020, 17, 5171. [CrossRef] [PubMed]

18. Gostin, L.O.; Salmon, D.A. The Dual Epidemics of COVID-19 and Influenza: Vaccine Acceptance, Coverage, and Mandates. JAMA 2020, 324, 335-336. [CrossRef] [PubMed]

19. Wolff, G.G. Influenza vaccination and respiratory virus interference among Department of Defense personnel during the 2017-2018 influenza season. Vaccine 2020, 38, 350-354. [CrossRef] [PubMed]

20. Ainslie, K.E.C.; Haber, M.; Orenstein, W.A. Challenges in estimating influenza vaccine effectiveness. Expert Rev. Vaccines 2019, 18, 615-628. [CrossRef] [PubMed]

Publisher's Note: MDPI stays neutral with regard to jurisdictional claims in published maps and institutional affiliations.

(C) 2020 by the authors. Licensee MDPI, Basel, Switzerland. This article is an open access article distributed under the terms and conditions of the Creative Commons Attribution (CC BY) license (http://creativecommons.org/licenses/by/4.0/). 